\title{
Revisión taxonómica del complejo Centaurea alba L. (Asteraceae) en la Península Ibérica
}

\author{
E. LÓPEZ \& J. A. DEVESA \\ Departamento de Botánica, Ecología y Fisiología Vegetal, Facultad de Ciencias, Campus de Rabanales, \\ Universidad de Córdoba, Ctra. de Madrid km 396, E-14071 Córdoba, España; \\ y Jardín Botánico de Córdoba, Avenida de Linneo s/n., E-14004 Córdoba, España
}

Autor para correspondencia: E. López (bv2lonie@uco.es)

Editor: L. Sáez

Recibido 28 marzo 2011; Aceptado 8 julio 2011

\begin{abstract}
Taxonomic revision of the Centaurea alba L. complex (Asteraceae) in the Iberian Peninsula.- A taxonomic revision of the Centaurea alba L. complex (Centaurea L. sect. Centaurea) in the Iberian Peninsula is presented, which is represented by two species, $C$. alba and $C$. costae Willk. Three subspecies of $C$. alba with reasonably well-defined areas are recognized: $C$. alba subsp. alba, with three varieties - alba, macrocephala Pau and latronum (Pau) E. López \& Devesa-, C. alba subsp. aristifera (Pau) E. López \& Devesa and C. alba subsp. tartesiana Talavera, two of them are proposed as new nomenclatural combinations. Centaurea costae is segregated from C. alba and three varieties are recognized: costae, montsicciana Pau \& Font Quer and maluqueri Font Quer. In the case of $C$. alba var. latronum, $C$. alba var. macrocephala and C. alba subsp. aristifera, the chromosome number was also studied $(2 n=18)$.
\end{abstract}

Key words: Asteraceae; Centaurea; chorology; Iberian Peninsula; taxonomy.

\begin{abstract}
Resumen
Revisión taxonómica del complejo Centaurea alba L. (Asteraceae) en la Península Ibérica.- Se efectúa la revisión taxonómica del complejo de Centaurea alba L. (Centaurea L. sect. Centaurea) en la Península Ibérica, representado por dos especies, $C$. alba y $C$. costae Willk. Para $C$. alba se reconocen tres subespecies con áreas bien definidas: $C$. alba subsp. alba, con tres variedades - alba, macrocephala Pau y latronum (Pau) E. López \& Devesa-, C. alba subsp. aristifera (Pau) E. López \& Devesa y C. alba subsp. tartesiana Talavera, proponiéndose dos nuevas combinaciones. Se segrega Centaurea costae de C. alba, y se reconocen para ella tres variedades: costae, montsicciana Pau \& Font Quer y maluqueri Font Quer. En el caso de C. alba var. latronum, C. alba var. macrocephala y C. alba subsp. aristifera se ha estudiado además el número cromosómico $(2 n=18)$.
\end{abstract}

Palabras clave: Asteraceae; Centaurea; corología; Península Ibérica; taxonomía.

\section{INTRODUCCIÓN}

El género Centaurea reúne unas 250 especies (Susanna \& Garcia-Jacas, 2007) con representación, sobre todo, en Europa, la Región Mediterránea y el SO de Asia, de las cuales unas 90 están representadas en la Península Ibérica. En su delimitación clásica el género es claramente polifilético (Susanna et al., 1995; Garcia-Jacas et al., 2000), por lo que su actual concepción, basada en numerosos estudios morfológicos (Bremer, 1994; Gabrielian, 1995; Wagenitz \& Hellwig, 1996) y filogenéticos (Susanna et al., 1995; Garcia-Jacas et al., 2000, 2001), ha entrañado una profunda reestructuración. 
Con la elección de Centaurea paniculata L. como nuevo tipo para el género (Greuter et al., 2001), la mayoría de los táxones de las secciones tradicionalmente reconocidas como Paniculatae (Hayek) Dostál (=Acosta Adans.; Holub, 1972), Willkommia Blanca y Phalolepis (Cass.) DC. -además de otras- se incluirían en el subgénero Centaurea. Todos ellos forman un grupo monofilético (Garcia-Jacas et al., 2006; Suárez-Santiago et al., 2007), hibridan con frecuencia (Ochsmann, 2000) y comparten el mismo tipo de polen derivado (tipo Jacea, de acuerdo con Wagenitz, 1955).

Aunque la mayoría de las especies del complejo Paniculatae-Willkommia-Phalolepis se encuentran en el Mediterráneo oriental y en la región Irano-Turania, existe un centro importante de diversificación en la Península Ibérica y el NO de África. De hecho, en la Península Ibérica el complejo comprendería en su actual delimitación 28 especies (unos 55 táxones), con un alto grado de endemicidad y conocida dificultad taxonómica, cuyo conocimiento deriva sobre todo de la síntesis de Dostál (1976) para Flora Europaea, así como de diversas aportaciones para el grupo de C. boissieri Willk. (Blanca, 1980a,b, 1981a-f, 1984, y Talavera, 1984b) y de $C$. paniculata L. (Arènes, 1949, 1951; López \& Devesa, 2008a- $d$, 2010; López et al., 2011).

Dentro del complejo, el tratamiento taxonómico del grupo de C. alba L. [tradicionalmente segregado como sect. Phalolepis (Cass.) DC.] en la Península Ibérica, ha sido muy desigual según los autores, sobre todo por su elevada variabilidad morfológica, que ha propiciado la descripción de diversos táxones infraespecíficos en alguna de sus especies, e incluso el reconocimiento de alguna más. De hecho, el propio Linné (1753), además de $C$. alba, describe C. splendens (Ind. loc.: "Habitat in Helvetia, Hispania, Sibiria"), especie que por la vaguedad de su descripción ha sido asimilada en muchas ocasiones a la anterior (v. gr., Lacaita, 1923), y también a $C$. costae Willk., por presentar brácteas involucrales obtusas, y no aristadas como en C. alba (Pau, 1916). Greuter (2003) resuelve el problema al designar un nuevo lectótipo para $C$. splendens [Herb. Linn. No. 1030.39 (LINN)!], que se correspondería entonces con $C$. margaritacea Ten., un endemismo ucraniano. También controvertida ha sido la identidad de $C$. deusta, descrita por Tenore (1815), y que autores como De Candolle (1838), Nyman (1878-1884) y Willkomm (1865) situaban en la Península Ibérica, pero que en tratamientos más recientes, como el de Dostál (1976, sub C. alba subsp. deusta), se circunscribe a Italia y a la Península Balcánica.

Un taxon tradicionalmente asimilado al grupo es C. latronum, descrito por Pau (1896) del C de España, y que difiere de C. alba sobre todo por sus "cabezuelas oblongas". La dificultad de su reconocimiento, por el escaso valor de los caracteres discriminantes, ha condicionado su tratamiento taxonómico posterior, bien como subespecie de C. alba (Dostál, 1976), o como variedad en este trabajo. También desigual ha sido el tratamiento de C. costae, descrita por Willkomm (1859) del NE de España, y que ha sido tradicionalmente subordinada a C. alba, ya sea como subespecie (Dostál, 1976) o como variedad (Bolòs \& Vigo, 1987). No obstante, a diferencia de $C$. alba $\mathrm{L}$. y de sus táxones infraespecíficos, los apéndices de sus brácteas involucrales medias son siempre más pequeños que la base de las mismas y son, por lo general, bilobados, múticos o cortamente mucronado-aristados. Sin duda, se trata de una especie muy afín, y ese es el criterio seguido en este trabajo.

En la última revisión del grupo para la Península Ibérica (Dostál, 1976), sólo se reconoce C. alba L., con las subespecies alba, latronum (Pau) Dostál y costae (Willk.) Dostál, si bien con posterioridad se describió una nueva subespecie (Talavera, 1984a), así como reconocido algunas variedades para $C$. costae (Bolòs \& Vigo, 1995).

En consecuencia, dada la dificultad descrita, recientemente se ha abordado una revisión taxonómica del grupo (López, 2008), de la que deriva el tratamiento dado en este trabajo. Éste incluye el reconocimiento de una nueva subespecie endémica del CE y NE de España, C. alba subsp. aristifera (Pau), y el de $C$. latronum Pau con rango varietal: C. alba var. latronum.

\section{MATERIALES Y MÉTODOS}

El estudio morfológico y biométrico en el que se fundamenta esta contribución, se ha llevado a cabo en material recolectado por los autores y en el conservado en diferentes herbarios $(\mathrm{BC}, \mathrm{BCN}, \mathrm{COFC}$, COA, COI, COI-Willk., JACA, JAEN, LISE, LISU, MA, MAF, SALA, SANT, SEV, UNEX), algunos de los cuales contienen material de interés para las lectotipificaciones, aunque otros han sido consul- 
tados exclusivamente a estos efectos (LINN, LYRouy, GE). La relación del material estudiado de cada taxon sólo incluye una selección de testigos de herbario para cada provincia o región, aunque para la confección de los mapas de distribución se han tenido en cuenta todos los pliegos analizados.

Para la transcripción de etiquetas en las distintas lectotipificaciones realizadas se ha usado una simplificación del método empleado por Burdet et al. (1981) utilizándose el estilo cursiva o itálica para el texto manuscrito, manteniéndose el estilo normal para a texto impreso, respetándose en este último caso el resto de formatos originales (mayúsculas, versales, etc.).

Los recuentos cromosómicos (en C. alba subsp. alba y subsp. aristifera) se han efectuado en células meristemáticas de raíces. Como antimitótico se utilizó 8- hidroxiquinoleina 0,002 M (Tjio \& Levan, 1950) y como fijador una mezcla de alcohol absoluto y acetato férrico (3:1). Para la tinción se utilizó carmín alcohólico-acético (Snow, 1963) actuando durante 24-48 horas. Para la descripción de la morfología de los cromosomas se ha seguido la terminología de Levan et al. (1964). El tamaño cromosómico se expresa mediante tres valores: la longitud del cromosoma más grande, la longitud media y su desviación típica (entre paréntesis) y el tamaño del cromosoma más pequeño, respectivamente.

\section{RESULTADOS Y DISCUSIÓN}

\section{Clave para las especies}

1. Brácteas involucrales medias con apéndice de 2,5-9 mm, orbicular, ovado o elipsoidal, igualando o de mayor tamaño que la base de la bráctea, con mucrón, arista o espina apical de 0,3-3 mm 1. C. alba

-. Brácteas involucrales medias con apéndice de 1,5-4 mm, generalmente bilobado, de menor tamaño que la base de la bráctea, mútico o a veces con un mucrón o arista apical de 0,2-1(1,6) mm

2. C. costae

\section{C. alba L., Sp. Pl.: 914 (1753)}

Phalolepis alba (L.) Cass. in F. Cuvier, Dict. Sci. Nat. ed. 2, 50: 249 (1827)

Ind. Loc.: "Habitat in Hispania"

Lectotypus (Talavera, 1984a: 247): "Herb. Linn. No. 1030.37." (LINN!)
Hierba perenne, inerme -excepto a veces las brácteas involucrales-, de un verde grisáceo a blanquecina, con pelos unicelulares y pluricelulares eglandulosos. Tallos hasta de $110 \mathrm{~cm}$, erectos o ascendentes, simples o ramificados por lo general desde la base o su parte media, no engrosados bajo los capítulos, de sección \pm prismática, acostillados longitudinalmente, no alados, por lo general poco foliosos, con indumento \pm laxo, de pelos pluricelulares rígidos $\mathrm{y}$ patentes, y pelos araneosos esparcidos. Hojas hasta de $18 \times 5 \mathrm{~cm}$, las basales pecioladas, dispuestas en roseta -a menudo secas en la floración-, enteras, pinnatífidas, pinnatipartidas o 1(2)-pinnatisectas, con lóbulos o segmentos ovados, oblanceolados o lanceolados, enteros o pinnatífidos, mucronados y de márgenes lisos o ligeramente aserrados, con haz de glabra a araneosa, y envés por lo general laxamente araneoso y con pelos pluricelulares, cortos y rígidos; las caulinares sésiles, no decurrentes, decrecientes en tamaño hacia arriba, con nerviación principal pinnada y nervio medio prominente por el envés, enteras, pinnatífidas, pinnatipartidas o pinnatisectas con 1-4 pares de lóbulos o segmentos oblanceolados, lanceolados o linear-lanceolados, enteros o pinnatífidos, el terminal por lo general más ancho, de oblanceolado a lanceolado o linear-lanceolado, de márgenes lisos y ligeramente revolutos, mucronadas, con haz de glabra a araneosa, y envés por lo general laxamente araneoso y con pelos pluricelulares antrorso-escábridos, cortos y rígidos. Capítulos homógamos, discoides, con las flores externas neutras y patentes, y las del centro hermafroditas y \pm erectas, terminales y axilares, solitarios o en conflorescencias corimbiformes laxas, alcanzados o no por las últimas hojas caulinares -que generalmente no sobrepasan el involucro-o sustentados por un pedúnculo blanco-tomentoso -al menos en su parte superior- de 5-50 mm. Involucro 9-19 × 4-16 mm, ovoide, globoso o cilíndrico, \pm redondeado o atenuado en la base, fuertemente sobrepasado por todas las flores del capítulo. Brácteas involucrales imbricadas y aparentemente aparentemente en 6-7 series, gradualmente crecientes en tamaño de fuera hacia dentro; las externas y medias de ovadas a ovado-oblongas, fuertemente adpresas, verdosas o amarillentas, con nervios longitudinales apenas marcados, con o sin márgenes estrechamente hialinos, glabras, con apéndice apical de 2,5-9 mm, igualando o de mayor tamaño que la base de la bráctea, orbicular, ovado o elipsoidal y cuculado, de erecto a erecto-patente, glabro o laxamente peloso 
y glanduloso, con glándulas translúcidas sésiles en el dorso, de margen entero, lacerado o ligeramente fimbriado en su parte superior, culminado por un mucrón, arista o espina apical de 0,3-3 mm; las internas 8,5-19 mm, lineares o linear-espatuladas, glabras, con márgenes estrechamente hialinos en toda su longitud, y apéndice apical apenas distinguible, de ovado a oblongo, plano o cóncavo, escarioso, entero, inerme o débilmente mucronado, de un verde claro. Receptáculo plano o ligeramente cóncavo, ligeramente alveolado, con páleas setáceas, lisas, comprimidas, agudas. Corola de las flores neutras de 10-22 mm, externa e internamente glabra, con tubo blanquecino y limbo de rosado a púrpura -rara vez enteramente blanca-, con 4-5 lóbulos de 2,5-6 mm; la de las flores hermafroditas de 10-14 mm, con tubo de 4-8 mm, blanquecino, y limbo de 6-8 $\mathrm{mm}$, rosado o blanquecino-rosado -rara vez corola enteramente blanca-, con 5 lóbulos de 2-4 mm, iguales o subiguales. Estambres con filamento homogéneamente peloso, con papilas hasta de $0,4 \mathrm{~mm}$, blanquecinos; anteras 4,5-8 $\mathrm{mm}$, blanquecinas o blanquecino-rosadas -con conectivo violáceo-, con apéndices basales de 0,3-0,7 mm, membranáceos y a menudo lacerados. Estilo blanquecino; ramas estigmáticas blanquecinas o rosadas. Aquenios 2,4-4 × 1,1-1,6 mm, homomorfos, todos con vilano, oblongo-obovoides u obovoides, comprimidos lateralmente, de sección elíptica, truncados y con reborde entero, en la madurez teñidos de verde obscuro o negro, con líneas longitudinales amarillas, laxa e inconspicuamente seríceo-vilosos; placa apical con nectario de 0,1-0,2 mm, pentalobulado, pardusco; hilo 0,4-0,9mm, lateral-adaxial; con eleosoma. Vilano doble, persistente, el externo con varias filas de páleas de $(0,5) 0,8-2,8 \mathrm{~mm}$ lineares, serradas, blanquecinas, y el interno con 1 fila de páleas lisas y aplanadas, laciniado-fimbriadas en el ápice, cortas, erectas y \pm conniventes.

Numero cromosómico: $2 n=18+0-2 \mathrm{~B}, 36+$ 0-4B (López \& Devesa, 2008c).

Floración: de abril a octubre.

Distribución general: Región Mediterránea.

Distribución en el territorio: C, CO, CN y SO de la Península Ibérica (Fig. 1).

Hábitat: Frecuente en claros y orlas de bosques -principalmente pinares, encinares y melojares- y matorrales, cunetas y bordes de caminos, taludes y baldíos, por lo general sobre suelos pedregosos o de textura gruesa, tanto de naturaleza calcárea como silícea, no excesivamente nitrificados; 3-2000 m.
Observaciones: En la Península Ibérica existen tres pautas de variación que han sido reconocidas aquí con categoría subespecífica. Por un lado, la subsp. alba, la más extendida en el territorio (C, $\mathrm{CN}, \mathrm{CO}$ y SO de la Península Ibérica), incluye los individuos con capítulos por lo general de mayores dimensiones, con involucro de 4-16 $\mathrm{mm}$ de anchura (aunque varía notablemente incluso dentro de una misma población), globoso u ovoide -rara vez subcilíndrico-, por lo general redondeado en la base.

C. alba subsp. tartesiana Talavera incluye individuos con tallos marcadamente escábridos, con hojas caulinares más anchas y capítulos con involucro subcilíncrico-fusiforme, de (4)5-9(10) $\mathrm{mm}$ de anchura, atenuado en la base. Su área de distribución se restringe al SO de España, a las sierras del sur de la provincia de Badajoz y las del norte de las de Huelva y Sevilla (Talavera, 1984a).

Finalmente, C. alba subsp. aristifera, descrita por Pau (1906) con categoría varietal y reconocida aquí como subespecie, incluye plantas procedentes del CE y NE de España (provincias de Cuenca y Zaragoza). Su principal carácter diagnóstico es la presencia en el apéndice de las brácteas involucrales de una espina apical bien desarrollada, de 1-3 mm, así como la posesión de hojas superiores pinnatipartidas o pinnatisectas, con 1-3 pares de lóbulos o segmentos oblongos, carácter que no comparten las otras subespecies reconocidas.

\section{Clave para las subespecies}

1. Apéndice de las brácteas involucrales medias con espina apical de 1-3 mm, erecta o erecto-patente; hojas superiores pinnatipartidas o pinnatisectas, con 1-3 pares de lóbulos o segmentos.

b. subsp. aristifera

-. Apéndice de las brácteas involucrales medias mucronado o con una espina apical de 0,3$1,5(2) \mathrm{mm}$, erecta; hojas caulinares superiores enteras, menos frecuentemente pinnatífidas o pinnatipartidas con 1 par de lóbulos o segmen....................................... 2

2. Hojas superiores linear-lanceoladas, aracnoideas; involucro de 4-16 $\mathrm{mm}$ de anchura, globoso u ovoide -rara vez subcilíndrico-, \pm redondeado o rara vez atenuado en la base a. subsp. alba

-. Hojas superiores elíptico-espatuladas, escábridas 


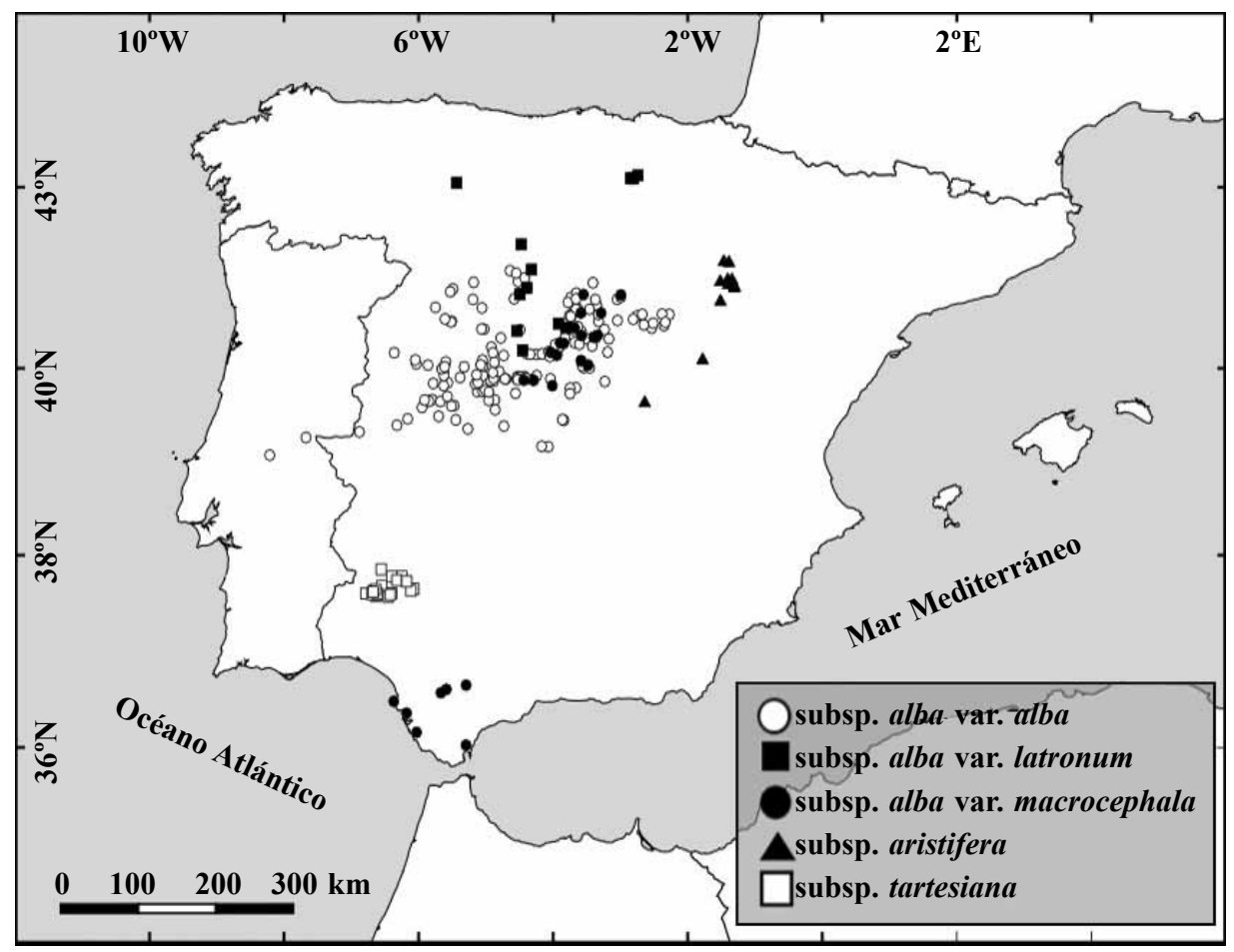

Figura 1. Distribución de Centaurea alba.

y glabriúsculas; involucro de (4)5-9(10) mm de anchura, \pm cilíndrico o fusiforme, débilmente atenuado en la base c. subsp. tartesiana

\section{a. subsp. alba}

Planta escábrida y con indumento de pelos araneosos. Tallos (5)10-80(110) cm. Hojas caulinares más superiores linear-lanceoladas, por lo general enteras, menos frecuentemente pinnatífidas o pinnatipartidas, con 1 par de lóbulos, aracnoideas. Involucro 9-19 $\times$ 4-16 mm, globoso u ovoide, rara vez \pm cilíndrico, redondeado o rara vez atenuado en la base. Apéndice de las brácteas involucrales medias elipsoidal, ovado u orbicular, con parte central elíptica y márgenes enteros, lacerados, denticulados o fimbriados en su parte superior, culminado en un mucrón, arista o espina de 0,3-1,5(2) mm. Aquenios 2,4-3,6 mm. Vilano externo $(0,5) 1-2,5 \mathrm{~mm}$.

Numero cromosómico: $2 n=18$ (López \& Devesa, 2008c).

Floración: de abril a octubre.

Distribución general: España y Portugal.

Distribución en el territorio: C, CN, CO y SO de la Península Ibérica (Fig. 1).
Hábitat: Claros y orlas de bosques -principalmente pinares, aunque también encinares, melojares, etc.-, matorrales, cunetas y bordes de caminos, taludes y baldíos, por lo general sobre suelos pedregosos o de textura gruesa, tanto de naturaleza calcárea como silícea, no excesivamente nitrificados; 3-2000 m.

Observaciones: Taxon extraordinariamente variable en lo concerniente al grosor de los capítulos, incluso en el seno de una población. Así, pueden observarse individuos con capítulos gruesos (involucro de 9-16 mm de anchura) o con capítulos pequeños (involucro de 4-7 mm), y también con capítulos intermedios (involucro de 5-11 $\mathrm{mm}$ ) entre ambos extremos. Estos últimos son los más abundantes y corresponden a C. alba s. s. (var. alba) siendo particularmente frecuentes en las sierras del Centro y Centro-Oeste de la Península Ibérica.

Las plantas con capítulos de involucro grueso y por lo general globoso, abundan sobre todo en sierras de la provincia de Madrid y se corresponden con C. alba var. macrocephala Pau (Pau, 1906), que coexiste en muchos lugares del centro peninsular con individuos de la var. alba. A esta variedad pertenecen también los individuos de un grupo de 
poblaciones del SO de España (provincia de Cádiz), indistinguibles de los del centro de la Península, ni morfológica ni cariológicamente, aunque muestran mayor variabilidad polínica (López, 2008).

La plantas con capítulos de involucro más estrecho, atenuado en la base y con el apéndice de las brácteas medias de tamaño similar al cuerpo de la bráctea, aparecen sobre todo en el norte del área de distribución de la subespecie. Esta variación, que ya fue descrita por Pau (1896, “...cabezuelas oblongas, escamas verdes inferiormente, nervosas y tan largas como el apéndice, que en el centro es triangular lanceolado") con categoría específica ( $C$. latronum), se considera aquí con categoría varietal.

\section{Clave para las variedades}

1. Involucro 4-7 $\mathrm{mm}$ de anchura, de ovoide a subcilíndrico, atenuado en la base, con apéndice de las brácteas medias de tamaño similar al resto de la bráctea ................................. $\boldsymbol{\beta}$. var. latronum -. Involucro 5-16 $\mathrm{mm}$ de anchura, de globoso a ovoide, redondeado en la base, con apéndice de las brácteas medias de mayor tamaño que el resto de la bráctea 2

2. Involucro de 9-16 $\mathrm{mm}$ de anchura, globoso; apéndice de las brácteas medias orbicular.................................... $\gamma$. var. macrocephala -. Involucro de 5-11 $\mathrm{mm}$ de anchura, globoso u ovoide; apéndice de las brácteas medias más o menos elíptico. a. var. alba

a. var. alba (Fig. 2, O)

C. strepens Hoffmanns. \& Link, Fl. Portug. 2: 236 (1820-1828) [Ind. loc.: "Près d'Abrantes sur le bord du Tage". Typus: non vidi]

C. alba subsp. strepens (Hoffmans. \& Link) Rocha Afonso in Bol. Soc. Brot. sér. 2, 54: 228 (1981) C. alba var. concolor DC., Prodr. 6: 569 (1838) [Ind. loc.: "In Hispania (Linn), Italia (Ten.), Dalmatia (Graf.!)". Lectotypus: non vidi]

C. segoviensis Rouy in Bull. Soc. Bot. France 52:
513 (1905) [Ind. loc.: "Espagne: prov.de Ségovie: bords des chemins et rochers au-dessous de l'Alcazar, vallon du Clamores (Rouy)". Lectotypus (designado aquí): "HERBIER G. ROUY / Plantes d'Algérie Espagne / Centaurea Segoviensis Rouy/ Đépartement Prov. de Segovia. / Segovia: rochers des bords des / chemins du val de Clamores. I 2 septbr 1905. Legi G. Rouy" (LY-Rouy s. n.!; segundo espécimen desde la izquierda, el más completo de los 5 que contiene el pliego)]

C. deusta var. heterochlamyda Sennen, Pl. Espagne. exsicc. 7154 (1929), nom. nudum, in sched. (BCSennen s. n.!, BC 84556! \& MA 133950!)

Involucro 9-17 × 5-11 mm, globoso u ovoide, redondeado en la base. Brácteas involucrales medias con apéndice de mayor tamaño que el resto de la bráctea, más o menos elíptico, con mucrón, arista o espina apical de 0,5-1,5(2) $\mathrm{mm}$.

Numero cromosómico: $2 n=18$ (López \& Devesa, 2008c).

Floración: de abril a octubre.

Distribución en el territorio: C y CO de la Península Ibérica (Fig. 1).

Hábitat: como la especie. 400-2000 m.

Material estudiado (selección): España. Ávila: La Adrada, 4.07.1984, P. Montserrat \& González (JACA 49884); Navacepedilla de Corneja, 13.07.2004, Devesa \& E. López (COFC 30409). Cáceres: Alcántara, 3.05.1994, Rico et al. (MA 718807); Puerto de Tornavacas, 1.07.1991, Ortega \& Tormo (UNEX 19546). Ciudad Real: El Molinillo, 6.07.1977, Velasco (MAF 99689). Guadalajara: Almadrones, 26.07.1970, Bellot et al. (MA 196860); Navalpotro, 3.05.1986, Monge \& Velayos (MA 531095). Madrid: Chamartín de la Rosa, 20.07.1929, Sennen \& Jerónimo (BC-Sennen s. n., BC 84556 \& MA 133950); El Escorial, 15.06.1852, Lange (MA 133966). Salamanca: Cantalapiedra, 20.06.1987, Aragón (SALA 46184); Villamayor, 25.07.1986, Guerrero \& Sánchez Rodríguez (SALA 41417). Segovia: Cantalejo, 3.07.1983, Romero (MA 569060); Rochers des bords des chemins du val de Clamores, 2.09.1905, Rouy (LY-Rouy s. n.). Toledo: Alcaudete de la Jara, 8.07.1967, Ladero

Figura 2. Centaurea alba subsp. aristifera (UNEX 34489): (A), porte; (B), nudo; (C), hoja basal; (D), capítulo; (E), bráctea externa del involucro; (F-G), brácteas medias del involucro; $(\mathrm{H})$, bráctea interna del involucro; (I), flor externa neutra; (J), flor interna fértil; $(\mathrm{K})$, corola de flor interna seccionada mostrando filamentos y una antera; (L), parte superior del estilo y ramas estigmáticas; (M), aquenio; (N), vilano mostrando verticilo interno. C. alba var. alba (MA 591892): (O), capítulo. C. alba subsp. tartesiana (UNEX 24423): (P), capítulo. Dibujos por Rodrigo Tavera. 


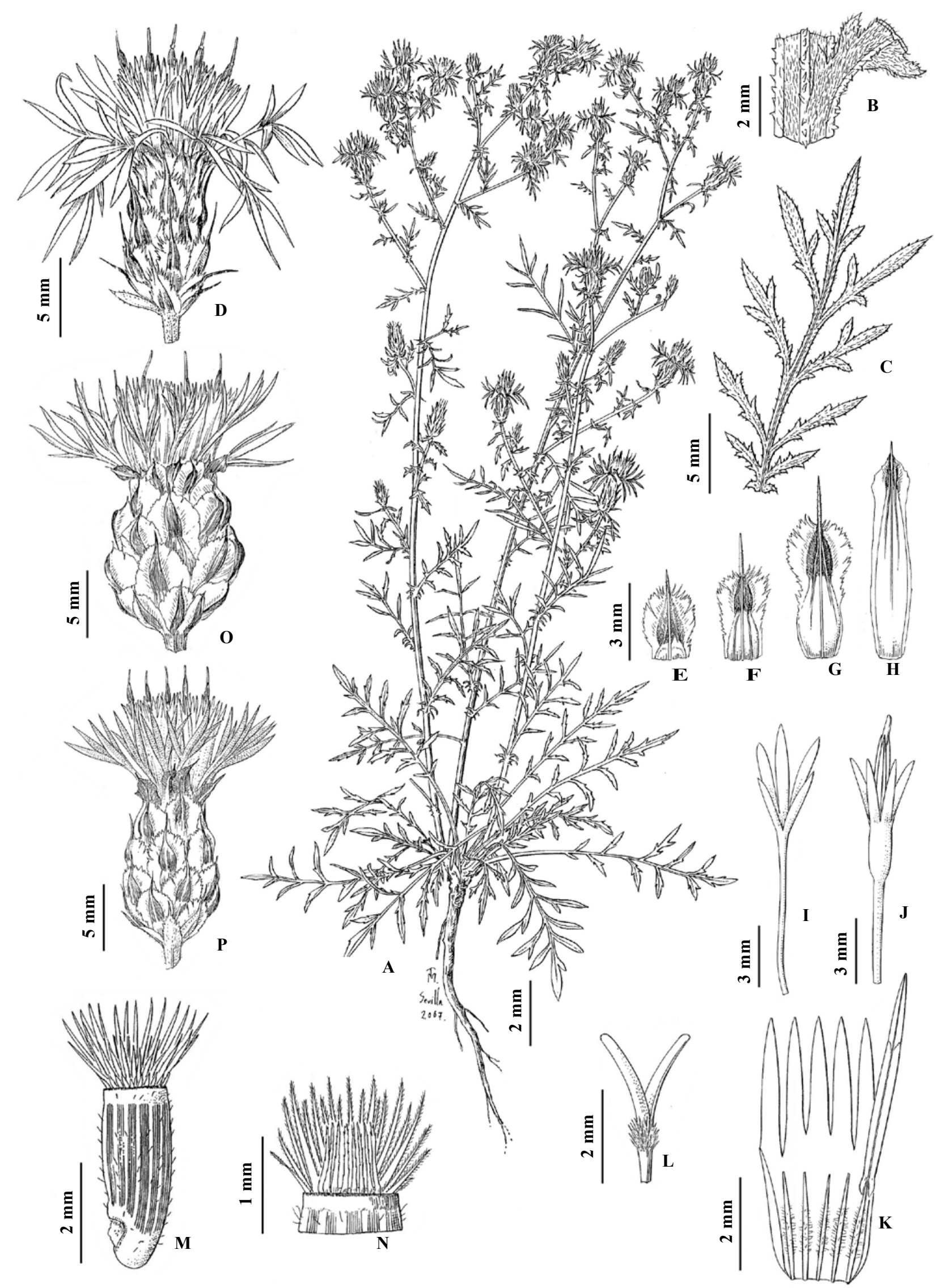


(MAF 80786); El Real de San Vicente, 18.06.2005, Arán (MA 751019). Valladolid: Boecillo, 07.1983, Ladero et al. (SALA 65831); Mojados, 2.07.1987, Burgaz \& Marcos (MA 411321). Zamora: Castrillo de la Guareña, 4.06.1981, Giráldez (SALA 31113); El Piñero, 19.06.1981, Giráldez (SALA 31177).

Portugal. Beira Baixa: Porto do Tejo, 8.06.1964, Fernández et al. (MAF 75541); Vila Velha de Rodão, 06 \& 07.1883, Da Cunha (COI 24233). Ribatejo: Abrantes, 24.08.1955, Rainha (LISE 47163); Entre a Praia e Tramagal, margem do rio Tejo, 09.1887, Da Cunha (LISU 39160).

及. var. latronum (Pau) E. López \& Devesa, comb. nova

C. latronum Pau, Not. Bot. Fl. Españ. 6: 67 (1896) [basión.]

C. alba subsp. latronum (Pau) Dostál in Bot. J. Linn. Soc. 71: 205 (1976)

Ind. Loc.: "Cerca de León y la Granja (Lomax, Julio 1892); Moncayo (B. Vicioso)"

Lectotypus (designado aquí): "Centaurea alba (L.) / var. deusta (DC.) / In ripis fluvii, prope urbem Leon, Hispania. / et prope La Granja. 21.7.92/ 17 de Julii, 1892. Legit. A. E. Lomax" (MA 133984!; ejemplar izquierdo, con más capítulos y mejor conservados que en el derecho)

C. latronum f. virens Pau in Bol. Soc. Aragonesa Ci. Nat. 6: 27 (1907) [Ind. loc.: "Miranda del Ebro (Sennen et Elias)". Lectotypus (designado aquí): "PLANTES D'ESPAGNE / Centaurea latronum Pau (vidit Pau) / $f^{a}$ virens / Castilla: Miranda de Ebro, estatión / 1906 8/8 Ho H. Elías" (MA 133995a!; ejemplar izquierdo, el único completo; Isotypus: MA 133995b!, BC 34767!)]

C. bolivaris Sennen nom. nudum, in sched. (MA 136595!)

C. deusta auct. hisp., non Ten., Fl. Napol. 1: 266 (1815)

Involucro 9-12 $\times$ 4-7 mm, de ovoide a \pm cilíndrico, atenuado en la base. Brácteas involucrales medias con apéndice de tamaño similar al resto de la bráctea, orbicular u ovado, con mucrón o arista apical de 0,4-1,1 $\mathrm{mm}$.

Número cromosómico: $2 n=18$ [Ávila: Entre Blascosancho y Hernansancho, 24.07.2009, E. López (COA 16441)]. La fórmula cromosómica es $8 \mathrm{~m}+1 \mathrm{sm}$ y el tamaño de los cromosomas $7,6 \mu \mathrm{m}$ - $(5,68 \mu \mathrm{m} \pm 0,99)-4,6 \mu \mathrm{m}$. Se trata del primer recuento efectuado para el taxon.
Floración: de junio a octubre.

Distribución en el territorio: $\mathrm{C}$ y $\mathrm{CN}$ de España (Fig. 1).

Hábitat: como la especie, pero con especial apetencia por los suelos silíceos; 450-1200 m.

Material estudiado (selección): España. Ávila: Ávila, 09.1900, Barras (MA 133988); Entre Blascosancho y Hernansancho, 24.07.2009, E. López (COA 16441). Burgos: Miranda de Ebro, 1914, Elias (MA 136595); ídem, estación, 8.08.1906, Elías (MA 133995 \& BC 34767). León \& Segovia: In ripis fluvii, prope urbem Leon, Hispania, et prope La Granja, 21.07.92 \& 17.07.1892, Lomax (MA 133984). Segovia: Fuente de La Granja, 08.1819, sin recolector (MA 160946); Segovia, 08.1916, C. Vicioso (MA 133983). Valladolid: Íscar, Puenteblanca, 20.08.1983, Fernández (MA 519345); Traspinedo - Sardón de Duero, 28.06.1974, P. Montserrat (JACA 330874).

$\boldsymbol{\gamma}$. var. macrocephala Pau in Bol. Soc. Aragonesa Ci. Nat. 15: 68 (1916) (Fig. 3)

C. alba subsp. macrocephala (Pau) Talavera in Lagascalia 12: 248 (1984)

Ind. loc.: "El Escorial (Secall!), cercanías del Hipódromo, Cercedilla, Torrelaguna, Pontón de Oliva, Navacerrada, Somosierra (Beltrán y Vicioso)".

Lectotypus (designado aquí): "Caroli Pau herbarium hispanicum / Centaurea alba L. / Madrid: a Hipódromo Legerunt Vicioso \& Beltrán VI.1912" (MA 133945!; espécimen central, el más completo y con mayor número de capítulos de los 3 que contiene el pliego).

C. appendiculata Lag. ex Colmeiro, Enum. Pl. Peníns. Hispano-Lusit. 3: 297 (1887), nom. nudum C. alba var. pseudodeusta C. Vicioso, nom. nudum, in sched. (MA 133956!)

C. latronum var. pseudodeusta C. Vicioso, nom. nudum, in sched. (BC-Sennen s. n.! \& MA 133955!)

Involucro 12-19 $\times 9-16 \mathrm{~mm}$, globoso, redondeado en la base. Brácteas involucrales medias con apéndice mayor que el resto de la bráctea, orbicular, con mucrón o arista apical de 0,5-1,5 mm.

Numero cromosómico: $2 n=18$ [Cádiz: ctra. de Arcos de la Frontera a Bornos, 8.06.2006, E. López (UNEX 34485)]. $8 \mathrm{~m}+1 \mathrm{sm}$; tamaño de los cromosomas 3,4 $\mu \mathrm{m}-(2,60 \mu \mathrm{m} \pm 0,49)-2,0 \mu \mathrm{m}$.

Floración: de mayo a agosto.

Distribución en el territorio: C y SO de España (Fig.1). 
Hábitat: como la especie; 3-1400 msm.

Material estudiado (selección): España. Ávila: Peguerinos, 17.07.1852, Isern (MA 133968); Sotillo de la Adrada, 15.06.1973, G. López \& Valdés-Bermejo (MA 443791). Cádiz: Algodonales, Sierra de Líjar, 17.06.1983, Aparicio \& Blázquez (SEV 208973); carretera de Arcos de la Frontera a Bornos, 8.06.2006, E. López (UNEX 34485). Guadalajara: Villacadima, 3.07.1975, Fdez. Casas \& García Guardia (JACA 543892). Madrid: Cercedilla, 07.1914, C. Vicioso (BC-Sennen s. n. \& MA 133955); Madrid, hipódromo, 06.1912, C. Vicioso \& Beltrán (MA 133945); Navacerrada, 2.11.1911, C. Vicioso (MA 133956). Segovia: Gallegos, 9.07.1982, Romero (MA 567896); Sepúlveda, 1.06.1986, Giráldez \& Romero (SALA 41702). Toledo: Méntrida, sin fecha, Cavanilles (MA 160962).

b. subsp. aristifera (Pau) E. López \& Devesa, comb. nova (Fig. 2, A-N)

C. aristifera Pau in Bol. Soc. Aragonesa Ci. Nat. 5: 234 (1906), pro hybr. [basión.]

Ind. loc.: "Calatayud, 3 Junio 1906. Rocas de las ruinas de Bílbilis".

Lectotypus (designado aquí): "Caroli Pau herbarium hispanicum / $\times$ Centaurea aristifera Pau / ( C. alba $\times$ Viciosoi Pau) / Calatayud 3-VI-1906 / Legit. C. Vicioso." (MA 136584 -con etiqueta original manuscrita- ejemplar superior derecho de los 5 que contiene el pliego; Isotypus: MA 136584! -con copia de etiqueta original-).

Planta con indumento araneoso laxo, a veces escábrida en tallos y envés de las hojas. Tallos (5)10-45 cm. Hojas caulinares más superiores pinnatipartidas o pinnatisectas, con 1-3 pares de lóbulos o segmentos oblanceolados o linear-lanceolados. Involucro 9-15 × 5-11 mm, ovoide o globosocilíndrico, redondeado en la base. Apéndice de las brácteas involucrales medias orbicular u ovado, con parte central \pm triangular y de un pardo obscuro o amarillento, y márgenes por lo general denticulados o lacerados, a veces fimbriados en la parte superior, culminado en una arista o espina de 1-3 mm, erecta o erecto-patente, cuya base a menudo se prolonga en una costilla amarillenta que recorre parte del apéndice. Aquenios 2,4-3,2 mm. Vilano externo 1-2 mm.

Numero cromosómico: $2 n=18$ [Zaragoza: entre Embid de la Ribera y Calatayud, 13.07.2006, E. López (UNEX 34489)]. La fórmula cromosómica es

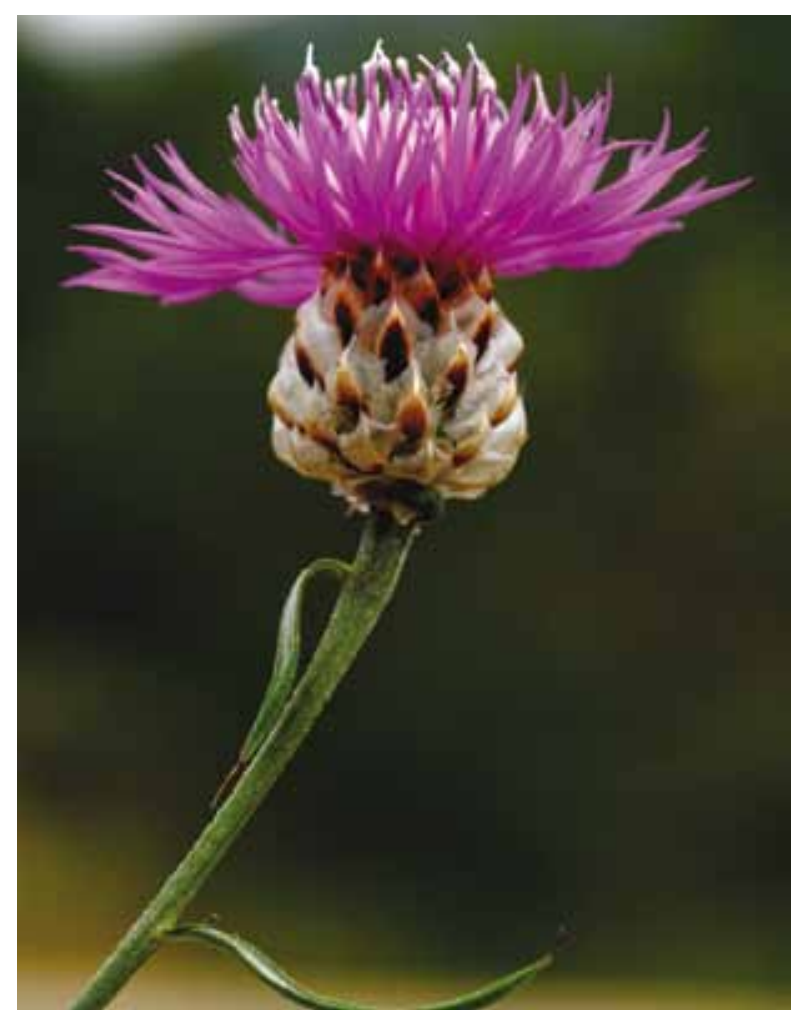

Figura 3. Centaurea alba var. macrocephala Pau (San Lorenzo del Escorial, Madrid).

$6 \mathrm{~m}+1 \mathrm{~m}^{\text {sat }}+2$ sm y el tamaño de los cromosomas $2,2 \mu \mathrm{m}-(1,70 \mu \mathrm{m} \pm 0,34)-1,2 \mu \mathrm{m}$. Es la primera vez que se estudia el taxon.

Floración: de mayo a agosto.

Distribución general: CE y NE de España (Fig. 1).

Hábitat: En baldíos, bordes de caminos, taludes y barrancos, con clara apetencia por suelos pedregosos de naturaleza calcárea y poco nitrificados; 530-1450 m.

Observaciones: En la provincia de Soria [España. Soria: entre Berlanga de Duero y Morales, 14.08.1978, Mateo (MA 442920); Ribarroya, 24.08.1982, Segura (MA 591316)] existen plantas con características intermedias entre esta subespecie y la subsp. alba. Presentan una altura de apenas $30 \mathrm{~cm}$, hojas superiores enteras o pinnatífido-pinnatisectas, y capítulos con involucro 10-12 $\times 5-8 \mathrm{~mm}$, ovoide-globoso, de base redondeada. El apéndice de las brácteas involucrales medias es entero o fimbriado en su parte superior, y culmina en un mucrón o arista de 0,5-1 mm.

De probable origen híbrido es Centaurea $\times$ bilbilitana Pau in Actas Soc. Esp. Hist. Nat. 23: 
137 (1894) $[=C \times$ bilbiltana $\mathrm{nm}$. paredensis $\mathrm{G}$. López in Anales Jard. Bot. Madrid (1980)], que presenta caracteres intermedios entre $C$. alba subsp. aristifera y $C$. pinnata $\mathrm{Pau}$, como son la posesión de capítulos con involucro cilíndrico y apéndice de las brácteas involucrales medias claramente pectinado-fimbriado.

Material estudiado (selección): España. Cuenca: El Tobar, 16.06.1979, G. López (MA 442892); Estrecho de Paredes, 29.06.1973, G. López \& Valdés-Bermejo (MA 444643). Zaragoza: Calatayud, 3.06.1906, C. Vicioso (MA136584 \& MA 136584); Entre Embid de la Ribera y Calatayud, 13.07.2006, E. López (UNEX 34489).

c. subsp. tartesiana Talavera in Lagascalia 12: 248 (1984) (Fig. 2, P)

Holotypus: "Huelva: Sierra de Aracena. Entre Aguafría y Quejigo. 19.07.1978. Leg.: J. Rivera" (SEV 49121!)

Planta con indumento araneoso laxo, marcadamente escábrida. Tallos (8)20-84 cm. Hojas caulinares más superiores enteras, elíptico-espatuladas, escábridas y glabriúsculas. Involucro 10-15 × (4)5-9(10) mm, subcilíndrico-fusiforme, débilmente atenuado en la base. Apéndice de las brácteas involucrales medias orbicular u ovado, con parte central elíptica, amarillenta o de un pardo claro u obscuro, y márgenes enteros, lacerados o pectinado-dentados, culminado en una arista o espina de 0,5-1,5(2) $\mathrm{mm}$. Aquenios 2,9-4 mm. Vilano externo 1,5-2,5(2,8) $\mathrm{mm}$.

Numero cromosómico: $2 n=18$ (López \& Devesa, 2008c).

Floración: de junio a septiembre.

Distribución general: Endemismo del SO de España (Fig. 1).

Hábitat: En orlas y claros de encinares, melojares o pinares, bordes de caminos y carreteras, sobre todo en suelos ácidos y ligeramente nitrificados; 500-1.000 m.

Observaciones: La subespecie convive en algunas partes de su área de distribución con C. cordubensis Font Quer, con la que a partir de cruces ancestrales originó probablemente C. schousboei Lange (López \& Devesa, 2008a).

Material estudiado (selección): España. Badajoz: Fregenal de la Sierra, 29.04.1988, Carrasco (UNEX 19548); Monesterio, 17.06.2003, E. López (COFC 30410). Huelva: Cortelazor, Casa La Cuadra, 04.06.1998, Morales (COFC 26586); Sierra de Aracena, entre Aguafría y Quejigo, 19.07.1978, Rivera (SEV 49121). Sevilla: El Real de la Jara, 6.06.1933, C. Vicioso (MA 133998); entre El Real de la Jara y Cazalla de la Sierra, 22.06.1976, Fernández Galiano et al. (SEV 121570).

\section{C. costae Willk. in Linnaea 30: 115 (1859) (Fig. 4)}

C. alba subsp. costae (Willk.) Dostál in Bot. J. Linn. Soc. 71: 205 (1976)

C. alba var. costae (Willk.) O. Bolòs \& Vigo in Collect. Bot. (Barcelona) 17(1): 91 (1987)

Ind. Loc.: "Hab. nostra species in Catalauniae ditione la Segarra, ubi cl. Costa eam prope San Ramon aliisque in locis d. 16. Julii 1858 florentem fructiferamque legit."

Lectotypus (designado aquí): " $C V I=C$. Costae $n$. Sp. Wk. / C. leucolepis? DC. / C. splendens L.? / St. Raimon y otros puntos de la Segarra / Julio 16 Costa" (COI-Willk. s. n.!).

Hierba perenne, inerme -excepto a veces las brácteas involucrales-, verde grisácea, con pelos unicelulares y pluricelulares eglandulosos. Tallos hasta de $50(95) \mathrm{cm}$, erectos o ascendentes, ramificados por lo general desde la parte media o superior, no o ligeramente engrosados bajo los capítulos, de sección \pm prismática, longitudinalmente acostillados, no alados, muy foliosos, con indumento generalmente laxo, de pelos pluricelulares rígidos y patentes, $\mathrm{y}$ pelos araneosos esparcidos. Hojas hasta de $13 \times 4 \mathrm{~cm}$, las basales pecioladas, dispuestas en roseta - a menudo secas en la floración-, enteras, pinnatipartidas o 1(2)-pinnatisectas, con lóbulos oblanceolados, lanceolados o linear-lanceolados, enteros o pinnatífidos, mucronados y con márgenes lisos o ligeramente aserrados, con haz glabriúscula o laxamente araneosa, y envés y

Figura 4. Centaurea costae var. costae (MA 34487): (A), porte; (B), nudo; (C), hoja basal; (D), capítulo; (E), bráctea externa del involucro; (F-G), brácteas medias del involucro; (H), bráctea interna del involucro; (I), flor externa neutra; (J), flor interna fértil; $(\mathrm{K})$, corola de flor interna seccionada mostrando filamentos y una antera; (L), parte superior del estilo y ramas estigmáticas; (M), aquenio; (N), vilano mostrando verticilo interno. C. costae var. maluqueri (MA 34486): (O), bráctea media del involucro. C. costae var. montsicciana (JACA 138270): (P), bráctea media del involucro. Dibujos por Rodrigo Tavera. 

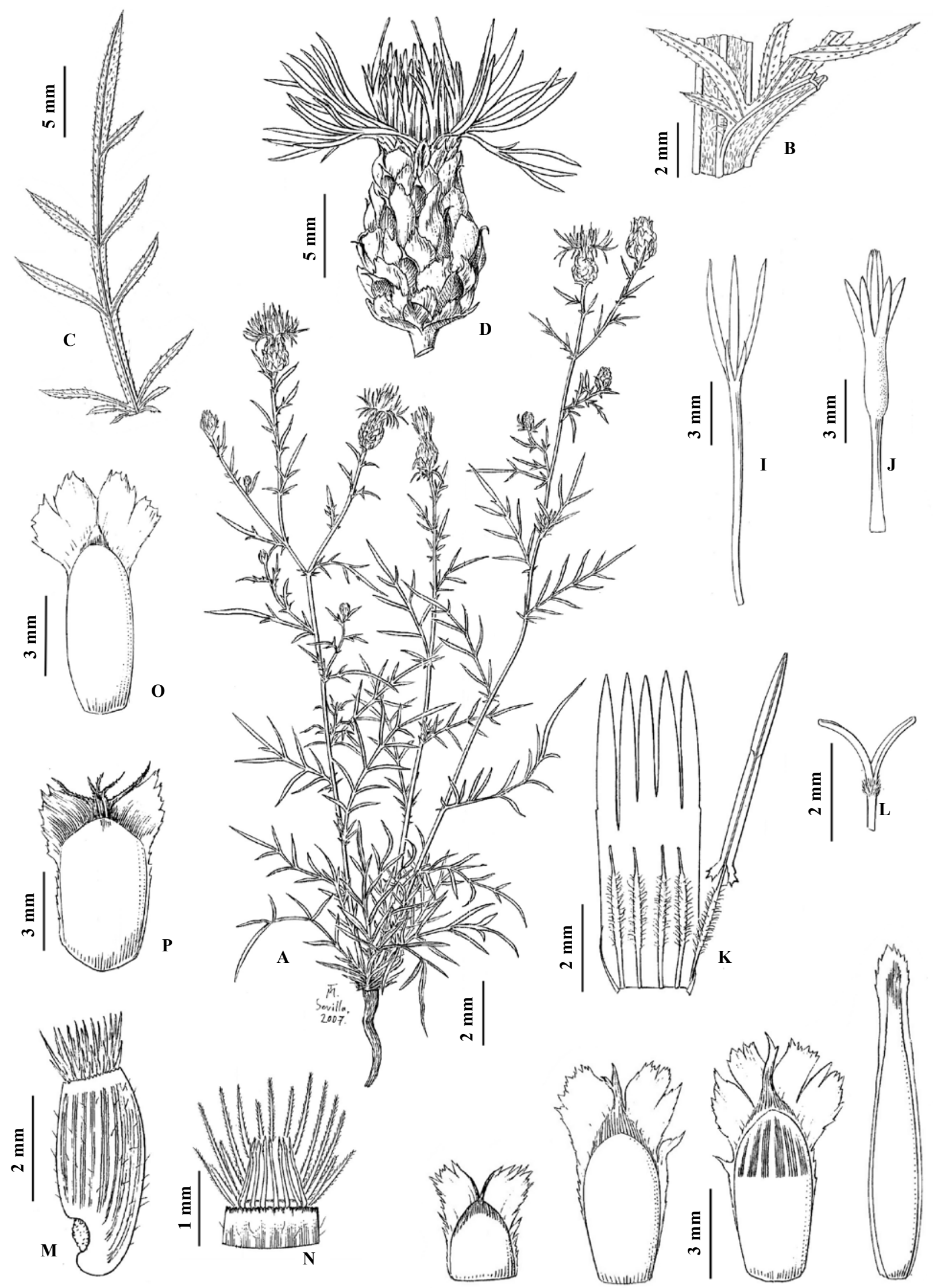

$\mathbf{E}$
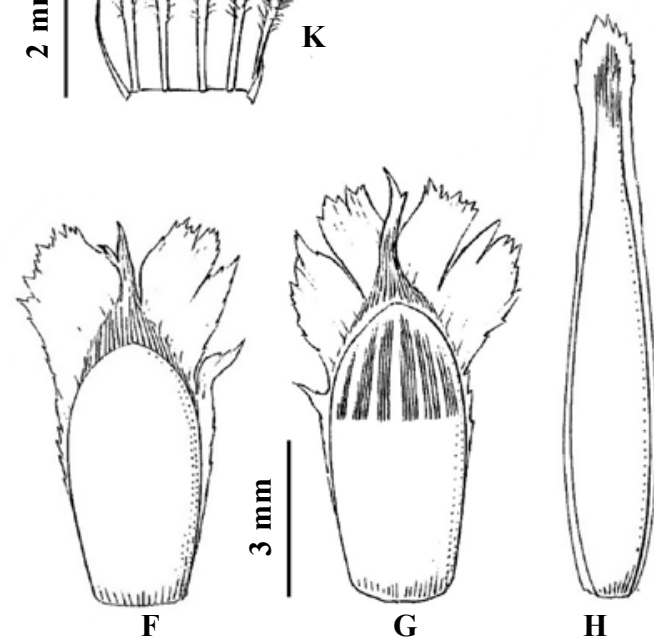
márgenes con pelos pluricelulares, cortos y rígidos; las caulinares sésiles, no decurrentes, decrecientes en tamaño hacia arriba, con nerviación principal pinnada y nervio medio prominente por el envés, enteras, pinnatipartidas o 1(2)-pinnatisectas y con 1-4 pares de lóbulos lanceolados o linear-lanceolados, enteros o pinnatífidos, el terminal por lo general más ancho, de lanceolado a linear-lanceolado, de márgenes lisos y ligeramente revolutos, mucronuladas, con haz glabriúscula, y envés y márgenes con pelos pluricelulares antrorsos, cortos y rígidos. Capítulos homógamos, discoides, con las flores externas neutras y patentes, y las del centro hermafroditas $\mathrm{y} \pm$ erectas-, terminales $\mathrm{y}$ axilares, solitarios o en conflorescencias corimbiformes laxas, terminales, a menudo alcanzados por la última hoja -que no sobrepasa el involucro- o sustentados por un pedúnculo blanco-tomentoso de $5-10 \mathrm{~mm}$. Involucro 10-16 × (5)6-12 mm, ovoide, redondeado en la base, fuertemente sobrepasado por todas las flores del capítulo. Brácteas involucrales imbricadas y dispuestas aparentemente en 6-7 series, gradualmente crecientes en tamaño de fuera hacia dentro; las externas y medias de ovadas a ovado-oblongas, fuertemente adpresas, verdosas, amarillentas o púrpureas en la parte superior de la base, con nervios longitudinales apenas marcados, de márgenes herbáceos o estrechamente hialinos, glabras, con apéndice apical de 1,5-4 mm, de menor tamaño que la base de la bráctea, bilobado o más rara vez orbicular, cuculado, erecto, erecto-patente o patente, glabro o laxamente peloso y glanduloso, con glándulas translúcidas sésiles en el dorso, con la parte central pardusca, de semilunar a triangular, y margen entero, denticulado o lacerado -a veces con (1)2-5 pares de fimbrias laterales- sobre todo superiormente, mútico o culminado por un mucrón o arista -simple o trífida- de 0,2-1(1,6) $\mathrm{mm}$; las internas de 9,5-16 mm, lineares o linear-espatuladas, glabras, con márgenes estrechamente hialinos en toda su longitud, y apéndice apical apenas distinguible, de ovado a oblongo, plano o cóncavo, escarioso, entero, inerme o rara vez con una espínula, de un verde claro. Receptáculo plano o ligeramente cóncavo, ligeramente alveolado, con páleas setáceas, lisas, comprimidas, agudas. Corola de las flores neutras de $12-17 \mathrm{~mm}$, con tubo blanquecino, y limbo de rosa a púrpura -rara vez enteramente blanca-, con 4-5 lóbulos de 2-6 mm; la de las flores hermafroditas de 10,5-13 mm, con tubo de 4,5-6 mm, blanquecino, y limbo 5,5-7 mm, rosado o blanquecinorosado -rara vez enteramente blanca-, con 5 lóbulos de 2,5-3,5 mm, iguales o subiguales. Estambres con filamento homogéneamente peloso, con pelos hasta de 0,2 mm, blanquecinos; anteras 5-6,5 mm, blanquecinas o blanquecino-rosadas - con conectivo violáceo-, con apéndices basales de 0,2-0,4 $\mathrm{mm}$, membranáceos y a menudo lacerados. Estilo blanquecino; ramas estigmáticas blanquecinas o rosadas. Aquenios 2,5-4,3 × 1-1,6 mm, homomorfos, todos con vilano, oblongoobovoides u obovoides, comprimidos lateralmente, de sección elíptica, truncados y con reborde entero, de un amarillo pajizo a verde obscuro o negro en la madurez, con líneas longitudinales amarillas, laxa e inconspicuamente seríceo-vilosos; placa apical con nectario de 0,1-0,2 mm, pentalobulado, amarillento; hilo 0,4-0,6 mm, lateral-adaxial, con eleosoma. Vilano doble, persistente, el externo con varias filas de páleas de 0,5-2,5 mm, lineares, serradas, blanquecinas, y el interno con 1 fila de páleas setáceas superiormente, cortas, erectas y \pm conniventes.

Numero cromosómico: $2 n=18$ (López \& Devesa, 2008c).

Floración: de mayo a octubre.

Distribución general: NE de la Península Ibérica (Fig. 5).

Hábitat: En orlas y claros de bosques (encinares, quejigales, robledales, hayedos y pinares), matorrales, bordes de cultivos, caminos, carreteras y taludes, sobre suelos ligeramente nitrificados, tanto de naturaleza calcárea como silícea; (100)450-1900 m.

Observaciones: En el herbario de Willkomm (Instituto Botânico Dr. Júlio Henriques de la Universidad de Coimbra; COI-Willk.) se conserva un pliego con cinco muestras de procedencia heterogénea. A las dos superiores, presumiblemente recolectadas por Costa, se asocia una etiqueta en la que puede leerse la anotación " $C$. costae n. sp. Wk." manuscrita por Willkomm, y la anotación locotípica: "St. Raimon y otros puntos de la Segarra.", también manuscrita pero probablemente de Costa; junto a esta etiqueta, además, una segunda etiqueta original contiene de la mano de Willkomm una prolija descripción de la especie. De estos dos especímenes se selecciona como lectótipo de C. costae Willk. el ejemplar superior izquierdo, que presenta más capítulos y mejor conservados. Esta elección coincide con la de Almeida (1984) quien indicó que en dicho pliego se conservaba el holótipo, mas sin designar cuál de los dos especímenes de esa misma localidad. Las restantes muestras fueron recolectadas por Soubervielle en "Aragon" (supuestamente el espécimen inferior izquierdo) y por Loscos (los dos restantes especímenes inferiores), también en Aragón ("Franc. Loscos, 


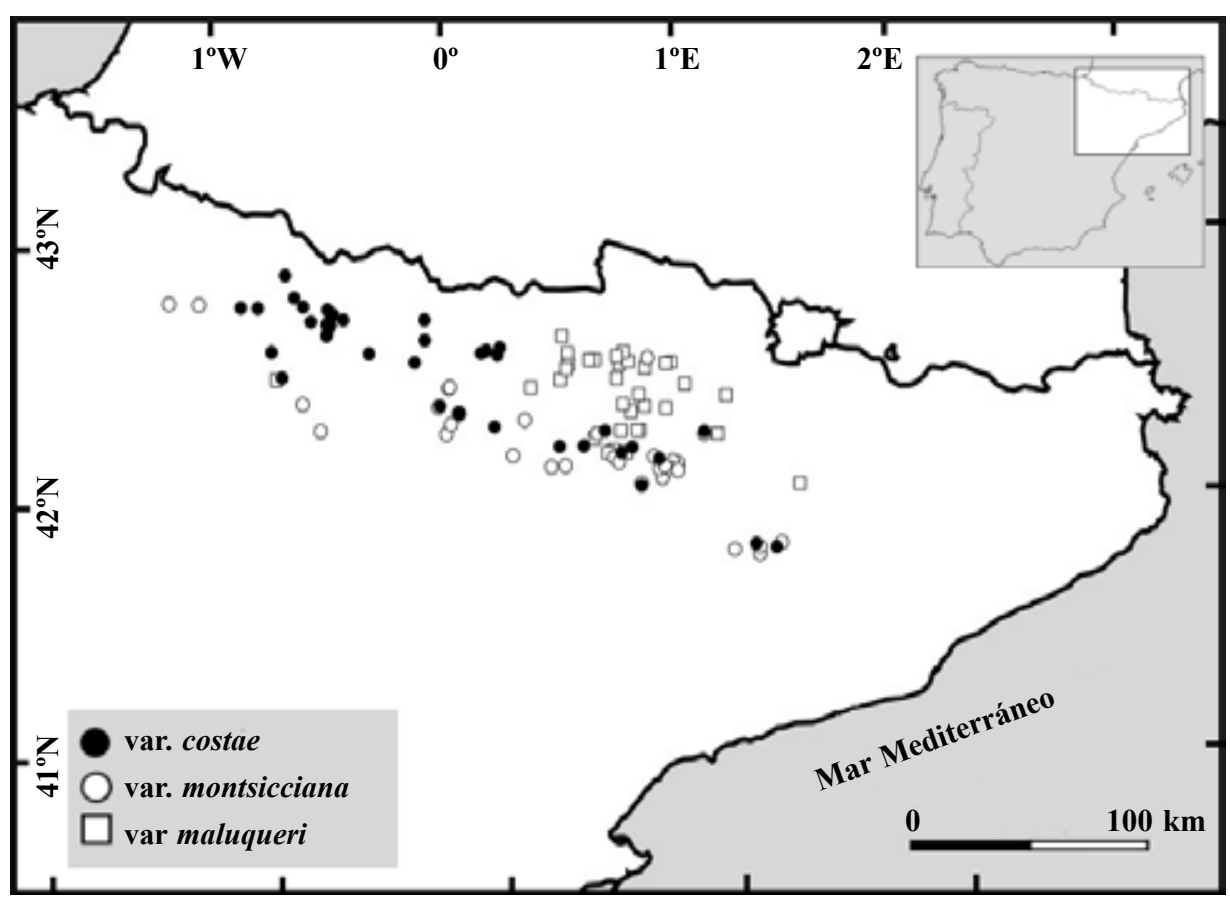

Figura 5. Distribución de Centaurea costae.

plantae Aragoniae australis / Centaurea australis Wk. / Prope. Chiprana Aranda del Conde / Leg. Calavia 1862 Det. Willkomm"), todas con fecha posterior a la publicación de la especie.

En el territorio estudiado se reconocen tres variedades atendiendo sobre todo a pequeñas variaciones en la morfología del apéndice: costae, montsicciana Pau \& Font Quer ex Font Quer y maluqueri Font Quer. Las tres presentan áreas de distribución más o menos simpátricas, coexistiendo con cierta frecuencia en una misma localización geográfica, a veces incluso las tres, como sucede en la Sierra del Montsec (Lleida), no siendo rara la aparición de individuos con caracteres intermedios.

\section{Clave para las variedades}

1. Apéndice de las brácteas involucrales medias mútico ................................. $\gamma$. var. maluqueri -. Apéndice de las brácteas involucrales medias con un mucrón o una arista apical, simple o trífida. ... 2

2. Apéndice de las brácteas involucrales con un mucrón apical ... a. var. costae -. Apéndice de las brácteas involucrales medias con una arista apical trífida ...... $\beta$. var. montsicciana a. var. costae (Fig. 4, A-N)

C. cinerascens Bubani, Fl. Pyren. 2: 161 (1900) [Ind. loc.: "Legi in Pyr. Arag. ad Jaca, die 24 Jul. 1858". Lectotypus (designado aquí): "Centaurea cinerascens Nob. / Flor. et fruct. Incipieb. 12.Jul.1898 / In Pyren. merid. Aragon. ad Jaca" (GE s. n.!; ejemplar de la parte inferior, el mejor conservado y más completo de los tres que contiene)]

C. alba var. cinerascens (Bubani) J.M. Monts., Fl. Veg. Sierra de Guara: 195 (1986)

C. aragonensis Bubani, Fl. Pyren. 2: 162 (1900) [Ind. loc.: "Legi supra Murillo Gallego in m. Rueva, die 29. Jun. 1850., in Sierra de Loarre die 19 Jun. 1858”. Lectotypus (designado aquí): “Centaurea eineraseens Nob. / matosa Lamk? / Flor. 29 Jun. 1850 / In Pyren. merid. Aragon. humil. / Supra Murillo Gallego montes Rueva /...." (GE s. n.!; ejemplar central izquierdo)].

C. pinae var. aragonensis (Bubani) J.M. Monts. in Collect. Bot. (Barcelona), 15: 329 (1984)

Apéndice de las brácteas involucrales medias 1,5-3 × 3-5 mm, más o menos orbicular, bilobado, con un mucrón distal de 0,3-0,5 (1) mm, erecto, parte central semilunar o anchamente triangular, y bordes enteros o denticulados.

Floración: de junio a octubre. 
Numero cromosómico: $2 n=18$ (López \& Devesa, 2008c).

Distribución general: NE de la Península Ibérica (Fig. 5).

Hábitat: En orlas y claros de bosques (encinares, quejigales, robledales, hayedos y pinares), matorrales, bordes de cultivos, caminos, carreteras y taludes, sobre suelos ligeramente nitrificados, tanto de naturaleza calcárea como silícea; 450-1420 m.

Material estudiado (selección): España. Barcelona/Lleida: La Manresana i S. Ramon, 27.07.1918, Font Quer (MA 134020). Huesca: Hecho, 7.08.1986, Ascaso \& Pedrol (MA 441597); Pirineo Aragonés, Jaca, 24.07.1858 \& 12.07.1898, Bubani (GE s. n.). Lleida: Montsec de Rubies, Urbanització Montsec, 3.07.1973, Camarasa (BC 699016); St. Ramon y otros puntos de la Segarra, 16.07., Costa (COI-Willk. s. n.). Zaragoza: Supra Murillo de Gállego, montes Rueva, 29.06.1850, Bubani (GE s. n.); Sigüés, Asso-Veral, 9.08.1969, P. Montserrat (JACA 668269).

及. var. montsicciana Pau \& Font Quer in Font Quer, Treb. Mus. Ci. Nat. Barcelona 5: 230 (1920) (Fig. 4, P)

C. alba var. montsicciana (Pau \& Font Quer) O. Bolòs \& Vigo in Collect. Bot. (Barcelona) 17(1): 92 (1987)

C. alba subsp. montsicciana (Pau \& Font Quer) Romo, Fl. Veg. Montsec: 304 (1989)

Ind. loc.: "Montsech de Ares, loco Coll d'Ares dicto". Lectotypus (designado aquí): "HERBARIUM FONT QUER / Centaurea Costae Willk. var. monsicciana Pau et F. Q. / C. cinerascens Bubani! / Hab. Montsec d'Ager, Coll d'ares, (Lleida) / Stat. Garrigues, 1000 m. alt. / Legi, 25 Juny 1916" (BC 34170!, de los 4 ejemplares que contiene se escoge el de la izquierda, de mayor tamaño, con más hojas y mayor número de capítulos; Isotypus: MA134022! \& MA 134023!). C. alba var. ciliata Font Quer ex O. Bolòs \& Vigo in Collect. Bot. (Barcelona) 17 (1): 92 (1987) [Holotypus: "Gerri de la Sal, in sterilibus, leg. P. Font i Quer, jul. 1918 (BC 34176)”!]

C. alba subsp. ciliata (Font Quer ex O. Bolòs \& Vigo) Greuter in Willdenowia 35(2): 227 (2005) C. segarrae Pau \& Font Quer in Treb. Mus. Ci. Nat. Barcelona 5: 230 (1920), pro hybr. [Ind. loc.: "Hab. Coll d'Ares (Montsech) inter parentes". Lectotypus (designado aquí): "HERBARIUM FONT QUER / Centaurea costae Willk. var. monsicciana Pau et F. Q. I fma. lacerata ad C. Sagarrae vergens / Hab. Montsec d'Ager, Coll d'ares, (Lleida) / Legi, 25 Juny 1916" (BC 34171!; de los dos ejemplares sin fijar que posee el pliego se escoge como lectótipo el de mayor tamaño)]

C. biformis var. oscilans Pau \& Font Quer, nom. nudum, in sched. (BC 34774!, BC 34775! \& BC 34782!)

Apéndice de las brácteas involucrales medias 2-3,5 $\times(3,5) 4,5-6 \mathrm{~mm}$, más o menos orbicular, bilobado, con una arista apical de $(0,3) 0,5-1,6 \mathrm{~mm}$, trífida, de erecta a patente, parte central anchamente triangular $\mathrm{y}$ bordes denticulados y/o lacerados, menos frecuentemente con 1-5 pares de fimbrias laterales.

Floración: de mayo a agosto.

Número cromosómico: no estudiado

Distribución general: NE de la Península Ibérica (Fig. 5).

Hábitat: En orlas y claros de bosques (principalmente encinares), matorrales, baldíos, taludes y bordes de cultivos, caminos, carreteras, sobre suelos ligeramente nitrificados, pedregosos, tanto de naturaleza calcárea como silícea; 450-1550 m.

Observaciones: El taxon, aunque poco variable en la mayoría de sus caracteres morfológicos, sí lo es en relación con el apéndice de las brácteas involucrales medias, pues o bien presenta sus bordes denticulados y/o lacerados o, en ocasiones, con 1-5 pares fimbrias laterales. Las plantas con este último carácter (BC 34176) fueron descritas como C. alba var. ciliata Font Quer, nombre que validarían con posterioridad Bolòs \& Vigo (1987). Dichas plantas, no obstante, entran dentro del rago de variación de C. costae var. montsicciana Pau \& Font Quer.

Material estudiado (selección): España. Barcelona: La Manresana, S. Ramon, 27.07.1918, Font Quer (BC 34169); Segarra, Calaf, 19.07.1870, Herb. Masferrer (BC 34172). Huesca: Estadilla, 7.06.1986, G. Montserrat (JACA 714486); Radiquero, Meseta de Anen, 19.07.1980, Martí (BC 676888). Lleida: Gerri de la Sal, in sterilibus, 07.1918, Font Quer (BC 34176); Montsec d'Ager, Coll d'ares, Garrigues, 1000 m, 25.06.1916. Font Quer (BC 34170, MA 134022 \& MA 134023); ídem, 25.06.1916, Font Quer (BC 34171); ídem, 25.06.1916, Font Quer (BC 34774, BC 34775 \& BC 34782). Navarra: Liédena, 1.07.1921, Font Quer (BC 34164); Sierra de Leire, 1.07.1921, Font Quer (BC 34164). 
$\boldsymbol{\gamma}$. var. maluqueri Font Quer in Treb. Mus. Ci. Nat. Barcelona 5: 230 (1920) (Fig. 4, O)

C. alba subsp. maluqueri (Font Quer) Molero \& Vigo in Treb. Inst. Bot. Barcelona 6: 24 (1981)

C. alba var. maluqueri (Font Quer) O. Bolòs \& Vigo in Collect. Bot. (Barcelona) 17(1): 91 (1987)

C. costae var. maluqueri f. robusta Font Quer, nom. nudum, in sched. (BC 34180)

Ind. Loc.: "Hab. in sterilibus pr. La Pobla de Segur". Lectotypus (designado aquí): "Museu de Catalunya / HERBARI / Centaurea costae Willk. / var. Maluqueri Font Quer / Hab. Pobla de Segur, Lleida / Stat. Garrigues, 650 m. alt. / Legit Font Quer, 5 Jul. 1918" (BC 34179!; Isotypus: MA 134021!).

Apéndice de las brácteas involucrales medias 2-4 $\times 3,5-6 \mathrm{~mm}$, orbicular, de bilobado a profundamente emarginado, mútico, con parte central tan ancha como larga y márgenes por lo general irregularmente lacerados en la parte superior.

Numero cromosómico: $2 n=18$ (López \& Devesa, 2008c).

Floración: de junio a octubre.

Distribución general: NE de la Península Ibérica (Fig. 5).

Hábitat: En orlas y claros de bosques (principalmente encinares, robledales y pinares), matorrales, taludes y laderas erosionadas, bordes de cultivos, caminos y carreteras, sobre suelos pedregosos ligeramente nitrificados, preferentemente de naturaleza calcárea; (100)560-1900 m.

Observaciones: En el herbario del Institut Botànic de Barcelona $(\mathrm{BC})$ se conservan 3 pliegos de "Centaurea costae Willk. / var. Maluqueri Font Quer" (BC 34175, BC 34179 y BC 34180) recolectados por Font Quer y procedentes de La Pobla de Segur (Lleida). En la etiqueta del pliego BC 34175 puede leerse "Hab. Claverol, pr. La Pobla de Segur (Lleida)", anotación que contiene un topónimo no recogido en la indicación locotípica, por lo que se excluye este material para la lectotipificación. Los otros dos pliegos, BC 34179 y BC 34180, poseen idéntica procedencia ["Hab. Pobla de Segur, Llei$d a$ "] pero fueron recolectados a diferente altura, 650 y $600 \mathrm{~m}$ respectivamente, y en uno de ellos (BC 34180) existe una pequeña anotación manuscrita de Font Quer, "form. robusta", si bien el material conservado presenta los capítulos escasamente desarrollados. Se elige para la lectotipificación el pliego BC 34179, que contiene 6 elementos, eligiéndose como lectótipo el ejemplar mayor y más completo, que ocupa la posición central.

De esta variedad existe un testimonio de herbario sin fecha y recolectado por Isern, en el que se anota "cerca de Gerona" (MA 134009). De ser fiable la procedencia, se ampliaría notablemente el área de distribución de esta variedad, algo que no ha podido ser comprobado in situ.

Material estudiado (selección): España. Huesca: Bonansa, 3.07.1987, Sesé \& G. Montserrat (JACA 642587); Castejón de Sos, 19.07.1903, Pau (MA 134024). Lleida: Montsec d'Ares, Alçamora, 30.06.1982, Romo (BC 699585); Pobla de Segur, Garrigues, 650 m, 5.07.1918, Font Quer (BC 34179).

\section{AGRADECIMIENTOS}

Este trabajo ha sido desarrollado en el contexto de la obra Flora Iberica, y financiado por los proyectos REN200204634-C05-04 y CGL2005-05471-C04-02, de la Dirección General de Investigación Científica y Técnica del Ministerio de Educación y Ciencia (ahora de Ciencia e Innovación). Nuestro agradecimiento a todos los responsables de los herbarios e Instituciones citadas y a Rodrigo Tavera por los dibujos. E. López estuvo adscrito como becario en formación (BES-20031275) a cargo de los proyectos citados.

\section{REFERENCIAS BIBLIOGRÁFICAS}

Almeida, M. T. 1984. On some type-specimens of "Centaurea" in Willkomm's Herbarium. 1. Webbia 38: 585-590.

Arènes, J. 1949. Les races lusitaniennes de Centaurea paniculata L. sensu latissimo. Agron. Lusit. 11: 5-32.

Arènes, J. 1951. Le groupe spécifique du Centaurea paniculata L. sensu latiss. Mém. Mus. Natl. Hist. Nat. Paris, Sér. B, Bot. 1: 175-266.

Blanca, G. 1980a. Dos táxones nuevos del genero Centaurea L. Anales Jard. Bot. Madrid 36: 143-152.

Blanca, G. 1980b. Notas cariosistemáticas en el género Centaurea L. Sect. Acrocentroides Willk. I. Anales Jard. Bot. Madrid 36: 349-369.

Blanca, G. 1981a. Revisión del género Centaurea L. sect. Willkommia G. Blanca, nom. nov. Lagascalia 10: 131-205.

Blanca, G. 1981b. Origen, evolución y endemismo en la sección Willkommia G. Blanca (gén. Centaurea L.). Anales Jard. Bot. Madrid 37: 607-618.

Blanca, G. 1981c. Consideraciones taxonómicas sobre la Centaurea rouyi Coincy (Compositae). Anales Jard. Bot. Madrid 38: 67-78.

Blanca, G. 1981d. Notas cariosistemáticas en el género Centaurea L. sect. Willkommia G. Blanca. II. Conclusiones. Anales Jard. Bot. Madrid 38: 109-125.

Blanca, G. 1981e. Estudios taxonómicos en la sección Willkommia G. Blanca (gen. Centaurea L.): brácteas involucrales. Trab. Dept. Bot. Univ. Granada 6: 61-89. 
Blanca, G. 1981f. Estudios taxonómicos en el género Centaurea L., sección Willkommia G. Blanca: Palinología. Bot. Macaronés. 8-9: 103-118.

Blanca, G. 1984. Sobre algunas centaureas del sur de España. Lazaroa 6: 169-174.

Bolòs, O. \& Vigo, J. 1987. Notes sobre taxonomia i nomenclatura de plantes, III. Collect. Bot. (Barcelona) 17(1): 89-93.

Bolòs, O. \& Vigo, J. 1995. Centaurea L. In: Bolòs, O. \& Vigo, J. (Eds.), Flora dels Països Catalans 3. Ed. Barcino, Barcelona: 912-945.

Burdet, H. M., Charpin, A. \& Jacquemoud, F. 1981. Types nomenclaturaux des taxa ibériques décrits par Boissier ou Reuter. I. Gymnospermes a Graminées. Candollea 36(2): 543-584.

Bremer, K. 1994. Asteraceae. Cladistic and classification. Timber Press, Portland.

Candolle, A.-P. de 1838. Prodromus systematis naturalis regni vegetabilis 6 . Paris.

Dostál, J. 1976. Centaurea L. In: Tutin, T. G., Heywood, V. H., Burges, N. A., Moore, D. M., Valentine, D. H., Walters, S. M. \& Webb, D. A. (Eds.), Flora Europaea 4. Cambridge University Press, Cambridge, London, New York, Melbourne: 254-301.

Gabrielian, E. T. 1995. On the generic status of certain groups of Centaureinae (Compositae). In: Hind D. J. N., Jeffrey, C. \& Pope, G. V. (Eds.), Advances in Compositae Systematics. Royal Botanic Gardens, Kew: 145-152.

Garcia-Jacas, N., Susanna, A., Garnatje, N., \& Vilatersana, R. 2001. Generic delimitation and phylogeny of the subtribe Centaureinae (Asteraceae): A Combined Nuclear and Chloroplast DNA Analysis. Ann. Bot. (Oxford) 87: 503-515.

Garcia-Jacas, N., Susanna, A., Mozaffarian, V. \& Ilarslan, R. 2000. The natural delimitation of Centaurea (Asteraceae: Cardueae): ITS sequence analysis of the Centaurea jacea group. Pl. Syst. Evol. 223: 185-199.

Garcia-Jacas, N., Uysal T., Romaschenko, K., Suárez-Santiago, V. N., Ertugrul, K. \& Susanna, A. 2006. Centaurea revisited: a molecular survey of the Jacea group. Ann. Bot. (Oxford) 98: 741-753.

Greuter, W. 2003. The Euro+Med treatment of Cardueae (Compositae) - generic concepts and required new names. Willdenowia 33: 49-61.

Greuter, W., Wagenitz, G., Agababian, M. \& Hellwig, H. 2001. Proposal to conserve the name Centaurea (Compositae) with a conserved type. Taxon 50: 1201-1205.

Holub, J. 1972. On correct generic names of Acrocentron Cass. and Acrolophus Cass. (Centaurea L. s.1.). Preslia 44: $215-218$.

Lacaita, C. 1923. Piante Italiane critiche o rare (LXXXIV-XC). Nuovo Giorn. Bot. Ital. ser. 2 30: 200-221.

Levan, A., Fredga, K. \& Sandberg, A. A. 1964. Nomenclature for centromeric position on chromosomes. Hereditas 52: 201-220.

Linné, C. 1753. Species plantarum... Salvii, Holmiae.

López, E. 2008. Estudio taxonómico de Centaurea sect. Paniculatae (Hayek) Dostál y sect. Phalolepis (Cass.) DC. en la Península Ibérica. Tesis Doctoral, Universidad de Extremadura.

López, E. \& Devesa, J. A. 2008a. Notas taxonómicas sobre el género Centaurea L. (Asteraceae) en la Península Ibérica. I. C. cordubensis Font Quer, C. bethurica E. López \& Devesa, sp. nov., y C. schousboei Lange. Anales Jard. Bot. Madrid 65: 331-341.

López, E. \& Devesa, J. A. 2008b. Notas taxonómicas sobre el género Centaurea L. (Asteraceae) en la Península Ibérica. II. C. castellanoides Talavera y C. aristata Hoffmanns. \& Link. Acta Bot. Malacitana 33: 57-68.

López, E. \& Devesa, J. A., 2008c. Contribución al conocimiento cariológico del género Centaurea (Asteraceae) en la Península Ibérica. Acta Bot. Malacitana 33: 69-90.

López, E. \& Devesa, J. A. 2008d. Notas taxonómicas sobre el género Centaurea L. (Asteraceae) en la Península Ibérica. III. C. limbata Hoffmanns. \& Link. Lagascalia 28: 411-423.

López, E. \& Devesa, J. A. 2010. Notas taxonómicas sobre el género Centaurea (Asteraceae) en la Península Ibérica. $C$. paniculata, C. hanryi y C. diffusa. Anales Jard. Bot. Madrid 67(2): 113-126.

López, E., Devesa, J. A. \& Arnelas, I. 2011. Taxonomic study in the Centaurea langei complex (Asteraceae). Ann. Bot. Fenn. 48 (En prensa)

Nyman, C. F. 1878-1884. Conspectus florae europaeae...I. Typis officinae Bohlinianae, Örebro.

Ochsmann, J. 2000. Morphologische und molekularsystematische Untersuchungen an der Centaurea stoebe L.-Gruppe (Asteraceae-Cardueae) in Europa. Diss. Bot. 324.

Pau, C. 1896. Notas botánicas a la flora española... 6: 66-67. Imprenta de Romaní y Suay, Segorbe.

Pau, C. 1906. Apuntes para la flora bilbilitana. Bol. Soc. Aragonesa. Ci. Nat. 5: 234.

Pau, C. 1916. Notas sueltas sobre la flora matritense II. Bol. Soc. Aragonesa Ci. Nat. 15: 63-74.

Snow, R. 1963. Alcoholic hydrochloric acid-carmine as a stain for chromosomes in squash preparations. Stain Technol. 38: 9-13.

Suárez-Santiago, V. N, Salinas, M. J., Garcia-Jacas, N., Soltis, P. S., Soltis, D. E. \& Blanca, G. 2007. Reticulate evolution in the Acrolophus subgroup (Centaurea L., Compositae) from the western Mediterranean: origin and diversification of section Willkommia Blanca. Molec. Phylogenet. Evol. 43: 156-172.

Susanna, A. \& Garcia-Jacas, N. 2007. Tribe Cardueae. In: Kadereit, J. W. \& Jeffrey, C. (Eds.), The families and genera of vascular plants, 8. Springer, Berlín, Heidelberg, Nueva York, Londres, París, Tokyo, Hong Kong, Barcelona: 123-147.

Susanna, A., Garcia-Jacas, N., Soltis, D. E. \& Soltis, P. S. 1995. Phylogenetic relationships in tribe Cardueae (Asteraceae) base on ITS sequences. Amer. J. Bot. 82: 1056-1068.

Talavera, S. 1984a. Centaurea alba L. en Andalucía Occidental. Lagascalia 12: 247-249.

Talavera, S. 1984b. Una nueva especie de Centaurea del sur de España. Lagascalia 12: 250-251.

Tenore, M. 1815. Flora Napolitana... 1: 266. Stamperia Francese, Nápoles.

Tjio, J. H. \& Levan A. 1950. The use of oxyquinoline in chromosome analysis. Anales Estac. Exp. Aula Dei 2: 21-64.

Wagenitz, G. 1955. Pollenmorphologie und Systematik in der Gattung Centaurea L. s. 1. Flora 142: 213-279.

Wagenitz, G. \& Hellwig, F. H. 1996. Evolution of characters and phylogeny of the Centaureinae. In: Hind D. J. \& Beentje, H. G. (Eds.), Compositae: Systematics. Proccedings of the International Compositae Conference, Kew, 1994, Royal Botanical Gardens 1: 491-510.

Willkomm, H. M. 1859. Pugillus plantarum novarum peninsulae pyrenaicae. Linnaea 30: 83-142.

Willkomm, H. M. 1865. Centaurea. In: Willkomm, H. M. \& Lange, J. M. Ch., Prodromus florae hispanicae... 2. Sumtibus E. Schweizerbart (E. Koch), Stuttgartiae: 138-169. 